Documentos 



\section{Universidade Virtual do Estado de São Paulo: breve histórico e perspectivas futuras}

\section{Carlos Vogt*}

\section{Programa Univesp}

O Programa Universidade Virtual do Estado de São Paulo - Univesp, criado pelo decreto $\mathrm{n}^{\circ} 53.536$ de 9 de outubro de 2008 e lançado em 26 de agosto de 2009, teve como principal foco a expansão do ensino superior público, gratuito e de qualidade no Estado de São Paulo, através da ampliação do número e da abrangência geográfica das vagas ofertadas.

Tratava-se de otimizar a utilização dos recursos humanos e materiais disponíveis nas universidades públicas paulistas e nas instituições parceiras, juntando-se recursos metodológicos e tecnológicos que possibilitem oferecer ensino superior público gratuito de alta qualidade para o maior número possível de estudantes do Estado.

Para a consecução dos objetivos do Programa, além das três universidades paulistas - Universidade de São Paulo (USP), Universidade Estadual de Campinas (Unicamp) e Universidade Estadual Paulista "Júlio de Mesquita Filho” (Unesp), contava-se com o Centro Estadual de Ensino Tecnológico Paula Souza (Ceeteps) e a Fundação Padre Anchieta (FPA) como instituições parceiras.

O Programa Univesp efetivou em 2010 a oferta dos cursos planejados e desenvolvidos ao longo dos anos anteriores. Assim, foram oferecidos à sociedade do Estado de São Paulo os cursos de graduação em Pedagogia, em parceria com a Unesp; licenciatura em Ciências e especialização em Ética, Valores e Saúde na Escola, com a USP; e os cursos extracurriculares de Inglês e Espanhol, com o Ceeteps. Em 2011, foi realizado o processo seletivo para a segunda turma do curso de licenciatura em Ciências Univesp/USP, além do lançamento e processo seletivo para a primeira turma da especialização em Ética, Valores e Cidadania na Escola, também com a USP. Em 2012, foram realizados os processos seletivos para a segunda turma da especialização em Ética, Valores e Cidadania na Escola e para a terceira turma do curso de licenciatura em Ciências Univesp/USP.

Em 2013, formaram-se 992 alunos da primeira turma do curso de graduação em Pedagogia e aconteceram os processos seletivos para a terceira turma da especialização em Ética, Valores e Cidadania na Escola e para a quarta turma da licenciatura em Ciências.

O primeiro curso oferecido no âmbito do Programa Univesp foi a graduação em Pedagogia, realizada em parceria com a Unesp. Trata-se de
${ }^{*}$ Professor titular na área de Semântica Argumentativa e Coordenador do Laboratório de Estudos Avançados em Jornalismo (Labjor) da Unicamp, é presidente da Fundação Universidade Virtual do Estado de São Paulo (Univesp). E-mail: <cvogt@univesp.br> 
um curso com 3.390 horas de atividades acadêmicas desenvolvidas em três anos, sendo 40\% delas realizadas presencialmente nos 22 polos de apoio distribuídos por 21 cidades do Estado. Foram ofertadas 1350 vagas no seu primeiro vestibular, realizado no final de 2009. Apesar da restrição dessas vagas serem apenas para professores em efetivo exercício nas redes pública e privada do Estado, o processo seletivo para o curso teve 7.987 inscritos, configurando a alta relação de 5,9 candidatos/vaga, que se caracteriza como 4,5 vezes maior que a média nacional (1,3 c/v) para Pedagogia no mesmo período.

Vale ressaltar os resultados obtidos apenas com a primeira oferta de curso do Programa Univesp. As 1350 vagas oferecidas para o curso de Pedagogia no ano de 2010 configuraram um aumento de $21 \%$ do total de vagas de graduação da Unesp, passando de 6.865 para 8.215. Se considerado o número total das três universidades públicas de São Paulo, o aumento nas vagas de graduação foi de $6,5 \%$. Por fim, a oferta do curso pela Univesp quase triplicou o número de vagas na soma da oferta das três universidades estaduais paulistas em Pedagogia, passando-se de 745 para 2095 vagas.

O segundo curso ofertado no âmbito do Programa Univesp foi o de especialização em Ética, Valores e Saúde na Escola, em parceria com a USP, pela Escola de Artes, Ciências e Humanidades (EACH-Zone Leste), que iniciou suas atividades em agosto de 2010. Trata-se de um curso de pós-graduação lato sensu com 456 horas de atividades acadêmicas desenvolvidas ao longo de 18 meses, sendo que 65\% dessa carga foram realizadas nos quatro polos de apoio presencial distribuídos pelo Estado, nas cidades de São Paulo, Campinas, São Carlos e Ribeirão Preto. No processo seletivo do curso foram oferecidas 350 vagas, para as quais houve 1.715 candidatos, alcançando-se uma alta relação de 4,9 candidatos por vaga, apesar da restrição de que os candidatos fossem professores em exercício nas redes pública e privada de ensino do Estado.

O terceiro curso oferecido pelo Programa Univesp foi o de licenciatura em Ciências, também em parceria com a USP. Trata-se do primeiro curso de graduação na modalidade semipresencial da instituição. O curso tem uma carga de 2.835 horas de atividades acadêmicas desenvolvidas em quatro anos, sendo que $48 \%$ dessas atividades ocorrem nos quatro polos de apoio presencial distribuídos nas cidades de São Paulo, São Carlos, Piracicaba e Ribeirão Preto. O curso visa à formação de professores de Ciências para o Ensino Fundamental, fato inédito nas universidades estaduais paulistas. No primeiro vestibular para o curso foram ofertadas 360 vagas, para as quais 1.773 candidatos se inscreveram, atingindo-se a relação de 4,92 candidatos/ vaga - valor significativamente maior que os obtidos por cursos similares da própria USP naquele ano, quais sejam o de licenciatura em Ciências da Natureza na USP-Leste (1,71 c/v) e o de Licenciatura em Ciências Exatas na USP-São Carlos (2,32 c/v). Esta oferta inicial de vagas para o curso de licenciatura em Ciências representou um aumento de 3,5\% do total de vagas 
de graduação da USP e, se somadas às vagas já oferecidas pelo curso de Pedagogia Univesp/Unesp, representaram um aumento de $8 \%$ do total de vagas de graduação das três universidades públicas paulistas. No segundo processo seletivo do curso, realizado no final de 2011, foram oferecidas mais 360 vagas, sendo 90 em cada polo (Piracicaba, Ribeirão Preto, São Carlos e São Paulo). No terceiro processo seletivo do curso, realizado em 2012, foram oferecidas mais 360 vagas, distribuídas da seguinte forma: Piracicaba (40 vagas), Ribeirão Preto (40 vagas), São Carlos (40 vagas), Santos (40 vagas), Lorena (40 vagas), Jaú (40 vagas) e São Paulo (120 vagas). A quarta turma, cujas atividades começam em 2014, conta com mais 360 vagas em sete cidades.

Outro curso de especialização da Univesp, de Ética, Valores e Cidadania na Escola, também realizado em parceria com a USP/EACH, teve início em 2011. No primeiro processo seletivo foram oferecidas mil (1.000) vagas distribuídas em 12 polos nas cidades de São Paulo, Ribeirão Preto, Bauru, Lorena, Piracicaba, São Carlos, Santos, Guarujá, São Vicente, Bertioga e Praia Grande. O curso tem duração de 18 meses e carga horária de 480 horas. O número de inscritos no processo seletivo para o curso alcançou a média total de 3,32 candidatos por vaga (C/V), o que confirmou a grande procura esperada. $\mathrm{O}$ processo seletivo para a segunda turma do curso ofereceu mais mil (1.000) vagas em 12 polos nas cidades de São Paulo, Campinas, Ribeirão Preto, São Carlos, Lorena, Bauru, Piracicaba, Santos, São Vicente, Guarujá, Jaú e Jundiaí. O número de inscritos no segundo processo seletivo para o curso alcançou a média total de 2,3 candidatos por vaga (C/V). A terceira turma, cujas atividades começaram em 2013, contou com mais 300 vagas em seis cidades. O processo seletivo teve uma relação de 7,3 candidatos por vaga.

Outra significativa realização do Programa Univesp foi a oferta dos cursos extracurriculares de Língua Inglesa e de Língua Espanhola para alunos do Ceeteps. Foram 10.000 vagas ofertadas para alunos da Região Metropolitana de São Paulo (RMSP), sendo 7.500 vagas para Inglês e 2.500 para Espanhol. Esses cursos, com duração de oito meses, foram realizados inteiramente pela Internet, mas com apoio presencial de tutores que ficaram à disposição dos alunos em várias unidades do Ceeteps na RMSP. Os cursos tiveram início em outubro de 2009, com uma oferta de 4.000 (quatro mil) vagas para Inglês e 1.440 (mil quatrocentos e quarenta) vagas para Espanhol. O restante das vagas foi oferecido a partir de março de 2010, encerrando-se em novembro do mesmo ano.

\section{Univesp TV}

Destaca-se ainda, como importante realização do Programa Univesp, a instalação e entrada em operação regular da Univesp TV. Trata-se de um canal digital aberto, exclusivamente dedicado à Univesp, que dá apoio aos 
cursos em andamento e oferece conteúdo de qualidade para a sociedade de uma forma geral. A Univesp TV é o canal 2.2 da multiprogramação da TV Cultura e se encontra no ar desde 26 de agosto de 2009. Desde sua criação, já foram produzidos mais de 900 horas de conteúdo original, distribuídos em 35 programas. O conteúdo pode ser acessado ao vivo também pela internet, na página do canal (http://univesptv.cmais.com.br/). O canal da Univesp TV no YouTube (http://www.youtube.com/user/univesptv), que foi ao ar em 26/04/2010, já obteve mais de 11,6 milhões de visualizações, 66 mil inscritos e 2,5 vídeos inseridos até meados de novembro de 2013. Esses números de acesso colocam a Univesp entre as 40 instituições universitárias de todo o mundo que mantêm canais próprios no YouTube.

\section{Revista eletrônica Pré-Univesp}

No âmbito de oferta de educação para a cidadania, houve o desenvolvimento da Pré-Univesp - revista digital de apoio ao estudante pré-universitário (http://www.univesp.ensinosuperior.sp.gov.br/preunivesp/), no ar desde junho de 2010. O conteúdo da Pré-Univesp, que é temático e mensal, está focado nos grandes assuntos da atualidade, presentes também na matriz curricular do ensino médio e nas questões das provas de ingresso à universidade. O objetivo da publicação é trazer conteúdo de qualidade e agradável voltado ao público pré-vestibulando, lançando mão de diversas mídias cabíveis na internet. $\mathrm{O}$ acesso ao conteúdo integral da revista é gratuito e o usuário pode se cadastrar e criar seu próprio arquivo de textos. Os assuntos são abordados de forma moderna e ágil, levando ao estudante os conteúdos através de reportagens instigantes, artigos, entrevistas e infográficos animados que são complementados por vídeos e textos literários, com linguagem motivadora para a juventude e por ela facilmente absorvida.

\section{Fundação Univesp}

Em 2012, uma das metas do atual Governo e uma das prioridades da Secretaria de Desenvolvimento Econômico, Ciência e Tecnologia do Estado de São Paulo começou a se concretizar: a transformação do Programa numa instituição com autonomia didático-científica, com a criação da Fundação Universidade Virtual do Estado de São Paulo - Fundação Univesp. A criação da Fundação Univesp ocorreu pela lei 14.836 de 20 de julho de 2012, estabelecendo-a como a quarta universidade pública paulista. O estatuto da Fundação foi aprovado pelo decreto 58.438 de 9 de outubro e, em 30 de outubro, Carlos Vogt foi nomeado Presidente da nova instituição. Em 21 de novembro foram nomeados os membros do Conselho Fiscal e, em 28 de novembro, foi constituído o Conselho Curador da Fundação Univesp. A escritura pública de instituição e constituição da Fundação Universidade Virtual do Estado de São Paulo foi assinada em 7 de dezembro de 2012. 
Foram nomeados Diretor Acadêmico e Diretor Administrativo da Fundação Univesp, respectivamente, Waldomiro Pelágio Diniz Carvalho Loyolla e Márcio Luiz de Andrade Netto.

O conceito fundamental sobre o qual se assenta o projeto da quarta universidade pública do Estado de São Paulo, na forma da Fundação Univesp, é o do conhecimento como bem público. A Univesp fará uso intensivo das novas tecnologias de informação e comunicação (TICs) para promover a evolução social do Estado, possibilitando a universalização do acesso ao ensino superior público e a universalização do acesso ao conhecimento na sociedade digital. É a tecnologia a serviço da educação e da cidadania, levando a educação de qualidade em todos os níveis para todas as regiões e Municípios do Estado.

Tais objetivos serão desenvolvidos a partir da oferta de vagas de graduação e de pós-graduação, na educação formal; e, na educação para a cidadania, na forma de cursos de extensão, de atualização e de educação continuada. A Univesp ministrará, ela própria, ou de forma consorciada com outras instituições de ensino, os cursos necessários visando à formação e ao aperfeiçoamento dos recursos humanos para prover o acesso ao conhecimento como bem público em todos os Municípios do Estado.

No aspecto da educação formal propõe-se o estabelecimento de uma política que continuadamente promova a ampliação da oferta de educação pública superior, em dois eixos complementares. O primeiro eixo corresponde ao aumento do número de cursos e de vagas públicas ofertadas à população. O segundo eixo corresponde à ampliação da abrangência geográfica da oferta de cursos públicos, de forma a prover educação superior em regiões não atendidas pelas Universidades Estaduais, sem ficar vinculado aos tradicionais padrões de implantação de campi universitários. Com isso, além de atender cidadãos de todos os Municípios do Estado, os cursos ofertados através da Univesp atuarão como indutores de desenvolvimento regional.

A Univesp servirá também como apoio acadêmico para diversas ações do Estado, desenvolvendo projetos em parceria com as Secretarias estaduais e outras instituições públicas, por exemplo, suprindo demandas específicas de formação, especialização e atualização de professores da rede estadual.

Nos aspectos social e cultural, a Univesp servirá como instrumento de uma política que continuadamente promova a educação para o exercício da cidadania, ao agregar possibilidades de criação de novos programas de integração social desenvolvidos com o lastro de uma instituição de ensino de qualidade. Tais iniciativas abrangerão não somente a inclusão digital de parte da população, como também o desenvolvimento de apoio acadêmico a programas de formação profissional para a inserção no mercado de trabalho, para a readaptação daqueles que foram desalojados 
profissionalmente pelas novas tecnologias ou mesmo para a geração de renda, o empreendedorismo e a geração de novos negócios.

A concepção acadêmico-administrativa da Fundação Univesp privilegia um modelo organizacional de pequeno porte corporativo (reduzido quadro permanente), mas moderno e de grande porte, pelo alcance, nos aspectos acadêmico, didático, social e geográfico, ao produzir cursos, obras de referência e materiais didáticos especificamente para a oferta de vagas com grande distribuição geográfica, e grande alcance social, através das TICs. Esse conjunto de características permite o desenvolvimento de pesquisas e a criação e oferta de cursos geridos como projetos. Neste modelo de gestão, a pesquisa e o curso (graduação, pós e extensão) existem pelo tempo necessário para cumprir os objetivos e as metas sociais estabelecidas no projeto. O pessoal acadêmico e técnico envolvido em cada projeto deverá ser contratado especificamente para o projeto em que participe.

Desse modo, a Univesp, emparelhada com as melhores tendências educacionais identificadas em todo o mundo, como entidade educacional ativa do Estado de São Paulo, virá contribuir de forma consistente para o atendimento da demanda por vagas no ensino superior público gratuito e de qualidade, levando a universidade ao aluno nas mais diversas regiões, e trazendo o estudante, antes nelas isolado, para a possibilidade real de integrar-se, pela universidade, às novas perspectivas profissionais abertas pelos cursos que lhe serão ofertados.

\section{Cursos e iniciativas de apoio: formação profissional integrada}

A estrutura dos cursos de formação profissional da Univesp se estabelece por "eixos profissionais". Isso permite que os alunos tenham uma formação integrada de tal maneira que possam, sequencial ou paralelamente, ampliar seus estudos e obter novas certificações, estendendo dessa forma o conceito de educação continuada.

Dentro de um mesmo eixo profissional, os cursos se apresentam com um núcleo de formação básica e, a seguir, com alternativas de trilhas profissionais correlatas de modo a permitir a seus alunos a escolha de uma ou mais habilitações profissionais nesse eixo. Assim, após a conclusão de uma saída profissional, o aluno poderá dedicar-se, pela escolha de uma nova trilha, à obtenção de um novo diploma de graduação, com aproveitamento total das disciplinas do núcleo básico comum.

Como exemplos dessa concepção integrada da estrutura dos cursos a serem oferecidos, podem-se citar:

a) Formação de profissionais para a área de Indústria, Comércio e Serviços no Eixo de Informática, com um núcleo básico e comum nos primeiros anos seguido, nos anos subsequentes, de alternativas de saídas profissionais, à 
escolha do aluno, para: Comércio Eletrônico, Segurança da Informação, Desenvolvimento de Sistemas, Sistemas de Informação, entre outras.

b) Formação de professores no Eixo de Linguagens e Humanidades, com um núcleo básico e comum nos primeiros anos composto por Linguística, Teoria Literária, Filosofia e Ciências Sociais e, nos anos seguintes, escolher uma dentre as possíveis trilhas cuja saída profissional seja Português, Língua e Literatura, Economia, Sociologia, Antropologia, Filosofia, Historia, Geografia, entre outras.

c) Formação de professores no Eixo de Ciências, com um núcleo básico e comum nos primeiros anos seguido, nos anos subsequentes, de alternativas de saídas profissionais, à escolha do aluno, para: Licenciatura em Ciências, em Matemática, em Física, em Química ou em Biologia.

A oportunidade aberta por esta concepção é, portanto, a de que o graduado num determinado eixo profissional possa, dentro dele, obter, com pleno aproveitamento das disciplinas do núcleo comum, mais de um diploma para o exercício de sua vida profissional.

\section{Programa de Inclusão com Mérito no Ensino Superior Público Paulista - PIMESP}

O Programa de Inclusão com Mérito no Ensino Superior Público Paulista - PIMESP, desenvolvido no âmbito do Conselho de Reitores das Universidades Estaduais de São Paulo - CRUESP, tem como metas garantir 50\% das vagas de cada curso e turno oferecidos pelas instituições de ensino superior público paulistas para alunos que cursaram integralmente o ensino médio em escolas públicas (EP), sendo que, destas vagas, 35\% serão preenchidas por pretos, pardos e indígenas (PPIs). As metas deverão ser escalonadas e atingidas em três anos, a partir de 2014.

O projeto reserva importante papel à Univesp, como a seguir exposto. A instituição, através do Instituto Comunitário de Ensino Superior - ICES, cuja criação está delineada no programa, oferecerá cursos superiores sequenciais com duração de dois anos. A seleção para ingresso será realizada de acordo com o desempenho dos candidatos no Enem. Serão ofertadas 2 mil vagas anualmente para alunos egressos de escolas públicas, sendo que, destas, 1.000 vagas serão destinadas a pretos, pardos e indígenas (PPIs).

Os concluintes do primeiro ano do curso sequencial oferecido pelo ICES com aproveitamento superior a 70\% terão ingresso garantido em cursos das Fatecs, com possibilidades de escolha da vaga conforme desempenho no curso. Os concluintes do segundo ano do curso, por sua vez, também com aproveitamento superior a 70\%, terão ingresso garantido em cursos das universidades estaduais e Fatecs, com possibilidades de escolha da vaga conforme desempenho no curso. 
Os cursos sequenciais oferecidos pelo ICES, através da Univesp, dessa forma, configuram uma nova modalidade de ensino superior no Estado, que, além de diplomar seus concluintes, também dão acesso direto às Universidades e Fatecs, contribuindo em conjunto com as medidas e programas desenvolvidos e adotados pelas Universidades e Fatecs, para o cumprimento das metas propostas no PIMESP.

Estão previstos investimentos no PIMESP no montante de R \$27,017 milhões em 2014, devendo atingir a R\$ 94,679 milhões em 2020. Nesse período, a oferta de vagas destinadas aos estudantes de escolas públicas será incrementada gradativamente, começando com 35\% em 2014, 43\% em 2015, alcançando 50\% em 2016.

Será criado fundo especial para bolsas assistenciais de permanência no valor de meio salário mínimo, destinadas aos alunos com renda familiar inferior a 1,5 salário mínimo. Os bolsistas serão avaliados mensalmente quanto à participação em atividades escolares.

\section{Considerações finais}

O sentido do conhecimento como bem público e a oferta de educação para o exercício da cidadania, fortemente presentes no projeto da Univesp, correspondem à ideia de alcançarem-se completamente todos e, particularmente, os mais distantes municípios de São Paulo. Isso, atualmente, somente se viabiliza pelo uso integrado das tecnologias disponíveis e através da intervenção institucional direta do Estado, no sentido de prover amplo acesso das mais distantes comunidades a essas tecnologias.

A Univesp busca usar as modernas tecnologias para promover a ampla inserção social e o pleno exercício da cidadania da população, através da universalização do acesso ao ensino superior público, gratuito e de qualidade, e da universalização do acesso ao conhecimento na sociedade digital. É a tecnologia a serviço da educação e da cidadania, levando o ensino superior de qualidade, para todas as regiões e municípios do Estado. 